\begin{tabular}{|c|c|c|}
\hline $\begin{array}{l}\text { ISSN 2525-4812 (versão online) } \\
\text { ISSN 2238-7641 (versão impressa) } \\
\text { http://www.revistaterceiramargem.com/ } \\
\text { index.php/terceiramargem/index }\end{array}$ & $\begin{array}{l}\text { Recebido em: 24/6/2019 } \\
\text { Aprovado em: 19/3/2020 } \\
\text { Período de publicação: jan./jun., } 2020\end{array}$ & $\begin{array}{c}\text { Revista Terceira } \\
\text { Margem Amazônia } \\
(\text { v. } 6 \cdot \mathrm{n} .14 \cdot \text { Jan./Jun. } 2020)\end{array}$ \\
\hline
\end{tabular}

Como citar o artigo:

MOREIRA, S. E.; SILVA, R. R. A importância da contabilidade para os pequenos produtores: um estudo de caso na feira Agroufam. Revista Terceira Margem Amazônia, v. 6, n.14, p. 93-101, 2020. DOI: http://dx.doi.org/10.36882/2525-4812. 2020v6i14p93-101

\title{
A IMPORTÂNCIA DA CONTABILIDADE PARA OS PEQUENOS PRODUTORES: UM ESTUDO DE CASO NA FEIRA AGROUFAM
}

Sílvia Elaine Moreira ${ }^{1}$

Rissia Ribeiro da Silva ${ }^{2}$

\begin{abstract}
Resumo: A contabilidade é uma ferramenta fundamental para a gestão de qualquer negócio, presente tanto nas grandes empresas como nos pequenos empreendimentos. Este trabalho tem como objetivo verificar a presença das Ciências Contábeis entre os participantes da feira denominada Agroufam, que ocorre dentro do campus da Universidade Federal do Amazonas (Ufam). A metodologia utilizada foi de abordagem qualitativa, estudo de caso com aplicação de questionário aos associados a Agroufam durante a sua $55^{\mathrm{a}}$ edição. A pesquisa demonstrou a presença de alguns controles contábeis entre os participantes por meio do registro de dados referentes a produção e venda dos produtos ofertados. Todavia observou-se a falta de utilização dessas informações em benefício do próprio negócio.
\end{abstract}

Palavras-chave: Agroufam, contabilidade, feiras, pequenos negócios.

\section{THE IMPORTANCE OF ACCOUNTING FOR SMALL PRODUCERS: A CASE STUDY AT THE AGROUFAM FAIR}

\begin{abstract}
Accounting is a fundamental tool for the management of any business, present in both large corporations and small enterprises. This work aims to verify the presence of Accounting Sciences among the participants of the fair that takes place inside the campus of the Federal University of Amazonas, called Agroufam. The methodology used was a qualitative approach, a case study with questionnaire application the ones associated to Agroufam during its 55th edition. The research demonstrated the presence of certain accounting controls among the participants through the recording of data related to the production and sale of the products offered. However, the lack of use of this information for the benefit of the business itself was observed.
\end{abstract}

Keywords: Agroufam, accounting, fairs, small business.

\footnotetext{
${ }^{1}$ Contadora, M.Sc. em Contabilidade e Controladoria, professora da Universidade Federal do Amazonas (Ufam), Manaus, AM. Email: semoreira@ufam.edu.br

${ }^{2}$ Contadora, Manaus, AM. Email: rissia18@hotmail.com
} 


\section{Introdução}

A contabilidade, ciência que tem por objetivo o estudo das variações quantitativas e qualitativas ocorridas no patrimônio das entidades, está presente em vários aspectos da sociedade atual, nas grandes corporações, em mercadinhos na esquina e até mesmo dentro da nossa própria casa, quando fazemos os controles mensais de nossas receitas e despesas. A Ciência Contábil é uma ciência dos fenômenos sociais e pode ser utilizada como ferramenta de controle de gastos, gerando benefícios a seus usuários. Todavia, em muitos casos, por desconhecimento, muitos não exploram as informações obtidas na contabilidade para a melhoria do seu negócio e, por conseguinte, da sua vida.

O fenômeno conhecido como globalização trouxe muitos avanços além do aspecto de comunicação; também aumentou consideravelmente o nível de concorrência entre os negócios, atingindo a todos que possuem algum empreendimento, seja ele de pequeno, médio ou grande porte, pois foi preciso se aprimorarem para manter-se no mercado. Neste cenário de alta competitividade, a contabilidade passou a ser utilizada como ferramenta de visibilidade, transparência e comunicação entre os setores econômicos e a sociedade, expandindo-se também para os pequenos negócios.

Toda e qualquer forma de empreendimento considerado bem-sucedido possui um bom gerenciamento interno, essa é a chave para sua manutenção em um mercado tão competitivo. Saber como levar o negócio adiante, por meio de planejamentos sólidos e gestão eficaz, se aplica a todos os tipos de empreendimentos não importando a área de atuação, sendo a contabilidade uma ferramenta que possibilita esse avanço. Mediante a necessidade minuciosa de controle dos gastos, receitas e despesas, tem-se a contabilidade de custos como uma das ramificações da Ciência Contábil, que é de suma importância para o bom gerenciamento dos investimentos nos mais diversos ramos de negócio.

Quanto às feiras, estas são conhecidas como representação de um fenômeno sociocultural e econômico, procedente dos aglomerados de pessoas, organizadas em barracas, que formam um grande espaço de comercialização, existente em grandes metrópoles ou em cidades interioranas, sendo consideradas, em alguns casos, um grande atrativo turístico, comercial e histórico em certas regiões. Nas feiras são comercializados diversos tipos de produtos (alimentos, artesanato, produtos agrícolas, etc.), com o intuito de oferecer mercadorias acessíveis e a preços mais baixos. Iniciadas nas ruas, essas feiras sofreram evoluções com o passar do tempo, ocorrendo uma transição da rua para lugares mais selecionados e, em alguns casos, se tornando eventos fechados que necessitam de procedimentos para poder deles participar.

Dentro dessa categoria atua a Agroufam, uma feira desenvolvida dentro do Núcleo de Socioeconomia da Faculdade de Ciências Agrárias da Ufam, a qual nasceu com o objetivo de ser um canal de escoamento da produção advinda da agricultura familiar do interior do Amazonas. Com sua expansão, surgiu também a possibilidade de participação para outros microempreendedores, como, por exemplo, os artesões, que são comerciantes muito presentes nas feiras. A oportunidade de demonstrar e vender seus produtos agrícolas ou artesanais na Agroufam pode ser considerada uma alternativa de renda em um mundo onde a competitividade atinge vários setores, além de oferecer um ambiente dinâmico e de maior facilidade para esses microempreendedores. 
Dentro deste contexto, esta pesquisa buscou verificar se os participantes da Agroufam, entre produtores rurais da agricultura familiar e os que trabalham com artesanato, desenvolvem algum tipo de controle contábil em suas atividades comerciais. Para isso foram entrevistados os participantes da $55^{\mathrm{a}}$ edição, levantando-se informações sobre os possíveis controles contábeis utilizados e, no caso de existirem, quais os mais usuais entre eles. Desta forma, pretende-se contribuir com a Ciência Contábil e sua importância para os micros e pequenos negócios, ajudando assim no desenvolvimento dos comércios locais e do meio social dos participantes da Agroufam.

\section{Agroufam}

O programa denominado Feira da Produção Familiar da Ufam (Agroufam) passou a ser parte do calendário permanente da Ufam a partir de 2014, tendo início em 2011 em caráter experimental pelo Núcleo Socioeconômico (UNIVERSIDADE FEDERAL DO AMAZONAS, 2015). Esse programa foi impulsionado pelo Projeto Fortalecimento da Organização Social e Identificação de Mercados Potenciais, visando à sustentabilidade em comunidades rurais do Amazonas, atendendo também pela sigla Osim. A feira ocorre nas primeiras quintas e sextas-feiras de cada mês, no minicampus da universidade, no hall da Faculdade de Ciências Agrárias (FCA).

A missão da Agroufam é o desenvolvimento rural sustentável articulado à extensão universitária, inovação, tecnologia, inclusão social, diversificação da renda da agricultura familiar, fomento às ações agroecológicas, à sustentabilidade ambiental, à segurança alimentar e nutricional e à soberania alimentar (FRAXE et al., 2015, p. 298). Embora, inicialmente, a feira tenha tido seu foco principal no agricultor familiar é expressiva a presença dos participantes da feira que trabalham com artesanato; portanto, hoje em dia, a feira se divide basicamente em dois grandes núcleos: agricultura e artesanato. Participam aproximadamente 130 empreendedores, entre agricultores e artesões, advindos de várias comunidades rurais pertencentes ao estado do Amazonas.

\section{Contabilidade de Custos}

Como ramificação da Ciência Contábil, a contabilidade de custos é uma das ferramentas de maior utilização para o desenvolvimento de um empreendimento, seja ele de grande, médio, pequeno ou de micro porte. Apresentando uma definição bastante clara sobre o assunto, Vanderbeck e Fagy (2001, p. 11) explicam que "a contabilidade de custos fornece os dados detalhados sobre os custos que a gestão precisa para controlar as operações atuais e planejar para o futuro do negócio".

Tem-se também que a contabilidade de custos é a área da contabilidade que trata dos gastos incorridos na produção de bens e serviços (FERREIRA, 2016, p. 3), uma área totalmente dedicada a controles sobre os gastos que são utilizados para fornecer produtos e serviços para a sociedade, como uma forma de oferecer ao usuário dessa ciência informações sobre o quanto ele gasta para manter o seu negócio. Definem também Crepaldi e Crepaldi (2018, p. 3) que:

[...] a contabilidade de custos é uma técnica utilizada para identificar, mensurar e informar os custos de produtos e/ou serviços. Tem a função de gerar informações precisas e rápidas para administração, para a tomada de decisão.

\begin{tabular}{l|l} 
Revista Terceira Margem Amazônia & v. 6 • n. 14 • Jan./Jun. 2020
\end{tabular} 
"Historicamente, a contabilidade de custos surgia com o advento das empresas industriais, a partir do século XVIII. Veio para atender a uma nova necessidade: atribuir custos aos estoques de produtos fabricados pelas empresas industriais" (RIBEIRO, 2018, p. 12). Mas, embora tenha começado com o objetivo de atender as necessidades das grandes indústrias, hoje em dia esse ramo da contabilidade destina-se a todos os múltiplos setores que necessitam desse tipo de controle, já que ela pode oferecer informações de custos sobre produtos, serviços, clientes, processos e outros detalhes que podem ajudar no gerenciamento de um negócio. Ao ter noção de seus custos, o gestor desenvolve melhor capacidade de controle, planejamento e tomadas de decisão. Deve-se destacar que ao implantar um sistema de custos na empresa este deve ser compatível com a estrutura interna organizacional, deve focar em seus procedimentos operacionais e no tipo de informação alvo para o qual se implantou o sistema.

Após os fatos apresentados pode-se entender que a utilização da contabilidade de custos tem a função de fornecer à administração de uma organização os dados referentes aos montantes de recursos gastos para manter o funcionamento da atividade comercial ou industrial, começando desde o processo administrativo até a venda do produto e/ou a prestação de serviços, além de auxiliar no conhecimento de quando o empreendimento passa a tornar-se lucrativo. Uma organização que conhece os benefícios da utilização de um sistema de custo, independentemente do seu porte, irá fazer bom uso das informações obtidas a fim de ajudar a gerir o negócio, pois mediante as dinâmicas complexas do mercado apresentadas hoje em dia, que imperam maior competividade, a boa utilização dessas informações pode fazer a diferença.

\section{Contabilidade Gerencial}

Segundo Marion e Ribeiro (2011, p. 2), “a contabilidade é uma ciência que tem por objetivo o controle do patrimônio das organizações". Para poder controlar esse patrimônio a contabilidade possui várias utilidades e ramificações que auxiliam nesse processo, uma delas é a contabilidade gerencial. Embora muitos autores conduzam a contabilidade gerencial para o contexto das grandes instituições comerciais, esse ramo da Ciência Contábil pode ser utilizado em todas as instituições, de pequeno a grande porte, para a obtenção de informações que venham a contribuir para o gerenciamento do negócio, por isso ela também deve ter participação na administração dos pequenos empreendimentos.

De acordo com Jiambalvo (2009), o objetivo da contabilidade gerencial para seus usuários é a geração de informações necessárias para planejamento, controle e tomada de decisão. Padoveze (2000, p. 28) nos apresenta o entendimento de que "a contabilidade gerencial significa o gerenciamento da informação contábil, isto é, significa o uso da contabilidade como instrumento de administração". Como Marion e Ribeiro (2011, p. 4) mencionam em seu livro:

Qualquer decisão a ser tomada, qualquer que seja a área de atuação do responsável por ela, encontrará na informação contábil gerencial o fundamento necessário para que a opção encontrada seja a mais benéfica possível para o desenvolvimento da organização.

Iudícibus (1998) explica que uma das funções mais importantes do processo de contabilidade gerencial é o armazenamento e a coleta de dados que serão processados no sistema de informação interno da empresa. Ou seja, a contabilidade gerencial existe a partir do momento em que 
existe uma coleta de dados e que, por meio do processamento dessas informações, irá influenciar no modo como ocorre o gerenciamento do negócio, por isso os dados coletados devem ser relevantes, o que leva ao entendimento de que, dependendo da empresa e sua principal função, os dados que serão considerados relevantes irão diferenciar.

Isso é mencionado também por Marion e Ribeiro (2011, p. 5):

Assim, a contabilidade gerencial poderá contemplar funções distintas de acordo com a natureza das decisões que objetiva orientar, conforme sua importância ou o estágio em que essas funções ocupam na gestão empresarial.

Assim sendo, o correto uso da contabilidade gerencial pode contribuir muito para o pequeno produtor rural e o artesão, uma vez que a utilização dessas informações contábeis pode levar à otimização dos processos produtivos dos seus pequenos negócios. A melhoria do gerenciamento interno na busca de aprimoramento é uma importante atitude para os microempreendedores se manterem no mercado de forma saudável e lucrativa.

\section{Metodologia}

De acordo com Fachin (2006, p. 30), o método é considerado um instrumento que dispõe aos pesquisadores uma orientação com o objetivo de facilitar o planejamento de uma pesquisa. $\mathrm{Na}$ elaboração deste trabalho foi realizada a aplicação de um questionário, que atingiu cerca de $30 \%$ dos participantes da feira da Agroufam, exclusivamente durante sua 55 edição, em dezembro de 2018. Com o objetivo de se obterem dados que respondessem ao questionamento dessa pesquisa foi aplicado um questionário com perguntas relativas aos possíveis controles contábeis das atividades dos entrevistados. Esta pesquisa se caracteriza como qualitativa, com objetivos exploratórios. Foi realizado um estudo de caso, com levantamentos bibliográficos, no qual se utilizou aplicação de questionário estruturado, com perguntas simples e diretas, tendo sido esclarecido aos que se disponibilizaram a responder que não precisariam se identificar.

Os dados obtidos na pesquisa são apresentados por meio de gráficos e divididos em tópicos baseados nas respostas.

\section{Resultados}

$\mathrm{Na} 55^{\mathrm{a}}$ edição da Agroufam foram entrevistadas 34 pessoas escolhidas de forma aleatória e que se mostraram abertas a responder ao questionário. A edição de dezembro/2018 contava com 112 associados. Os resultados da pesquisa são demonstrados nos gráficos a seguir.

A Figura 1 contempla as respostas ao seguinte questionamento: "Possui controle dos custos de produção do que está sendo vendido nesta edição da Agroufam?". Dos que afirmaram possuir controle de custos, as respostas divergiam quanto às formas de controle. Entre os tipos mais mencionados na resposta estão: a realização do registro dos custos em cadernos, com informações sobre o preço das matérias-primas, os valores monetários para se manterem na feira durante os dois dias, as quantidades produzidas e o preço de venda dos produtos. Os entrevistados admitiram não possuir nenhum conhecimento formal sobre Ciências Contábeis, assim sendo desconhecem 
seus princípios e as peculiaridades relacionadas à área. Todavia, mesmo sem conhecerem os fundamentos da referida ciência, fazem uso de um de seus princípios básicos, o Princípio do Registro pelo Valor Original, que trata da realização de registros no momento da ocorrência dos fatos e atos da atividade econômica. Para aqueles que responderam que não possuíam nenhum tipo de controle sobre os custos de suas atividades, pode-se verificar dois principais motivos. O primeiro relatado foi a falta de conhecimento por parte dos entrevistados de como se poderia realizar um controle sobre os custos de maneira eficiente para conhecer mais profundamente o seu negócio e melhorar suas tomadas de decisão. O segundo motivo foi a falta de costume em controlar custos, apesar de acharem uma boa ideia.

Figura 1. Controle dos custos de produção.

\section{Controle de Custo}

não possui controle sobre os custos Possui controle sobre os custos

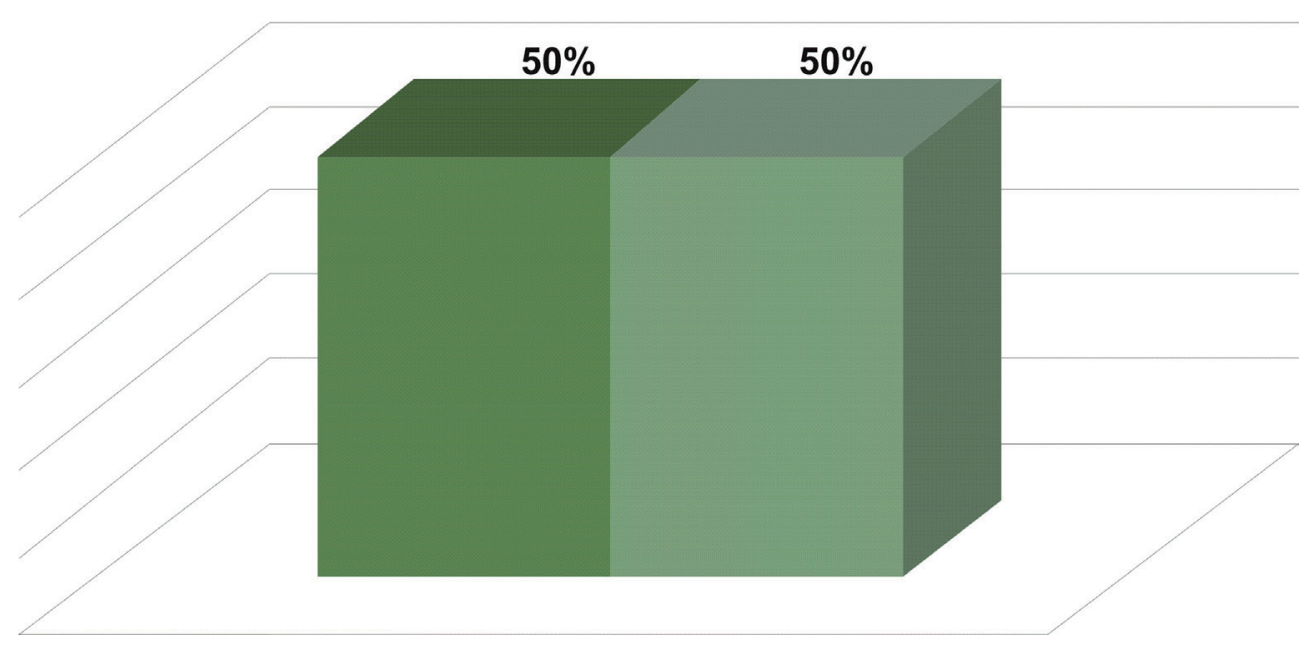

Fonte: Elaborado pelas autoras com base na coleta de dados.

Perguntou-se aos entrevistados se eles possuíam algum controle de quanto foi obtido com as vendas naquela edição da feira. Assim, a Figura 2 mostra que 79\% dos entrevistados realizam algum controle sobre as vendas; já o correspondente a $21 \%$ informou não realizar nenhum controle sobre as vendas. Os que responderam de maneira negativa retratam novamente os motivos que foram mencionados por aqueles que não realizam controle sobre os custos, a falta de iniciativa própria em relação ao próprio empreendimento, sendo mencionada também a falta de costume de realizar esse tipo de controle sobre o empreendimento.

A Figura 3 demonstra as respostas ao seguinte questionamento: "O dinheiro obtido com a venda nesta $55^{\text {a }}$ edição foi suficiente para cobrir os custos da atividade?". Em resposta, 35\% afirmaram que obtiveram retorno acima do investimento inicial; $8 \%$ responderam que, mesmo fazendo os procedimentos de registro dos custos e vendas, não conseguiram o retorno do investimento. Os participantes classificados dentro dos $62 \%$ são aqueles que admitem não saber se obtiveram lucro ou prejuízo na atividade. Aqueles que possuíam somente um dos métodos de controle mencionados anteriormente, ou seja, o de vendas, acreditavam ter tido algum retorno positivo sobre o investimento inicial, alegando que o dinheiro obtido com as vendas era suficiente para cobrir os 
gastos com o empreendimento. Todavia, quando questionados como poderiam ter certeza disso, se não realizavam anotações das informações sobre os custos de produção, uma vez que para se conhecer o lucro ou prejuízo do negócio há que se contabilizar, com o máximo de precisão, todos os custos, despesas e receitas da atividade produtiva, eles afirmaram que não poderiam ter certeza dos seus resultados.

Figura 2. Controle sobre vendas.

\section{Controle sobre Vendas}

não possui controle sobre as vendas Possui um controle sobre as vendas

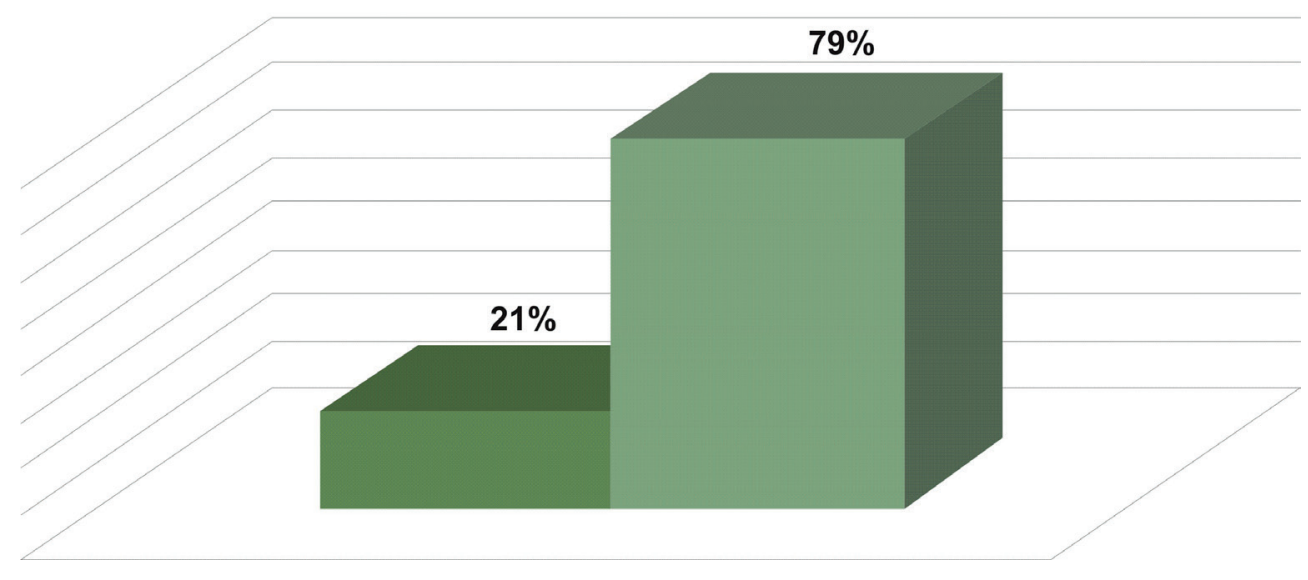

Fonte: Elaborado pelas autoras com base na coleta de dados.

Figura 3. Retorno do investimento.

\section{Retorno do Investimento}

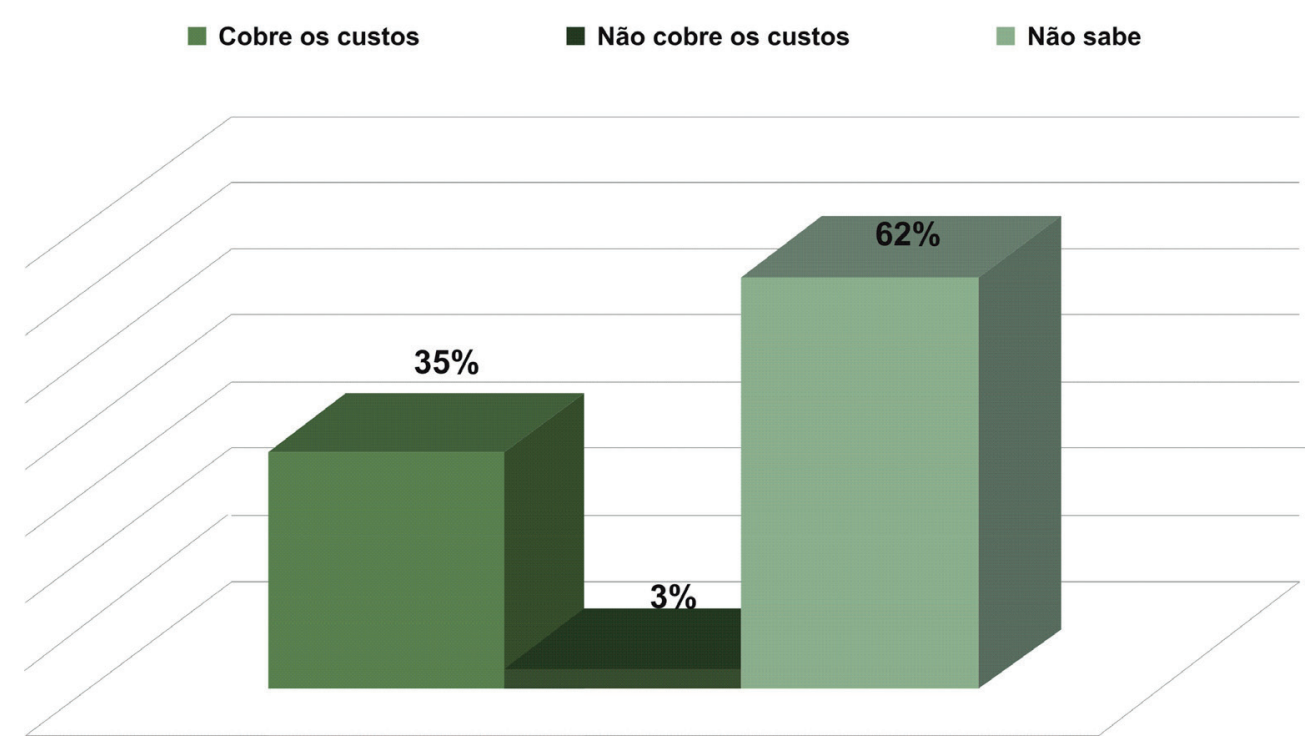

Fonte: Elaborado pelas autoras com base na coleta de dados. 
Para finalizar o questionário, foi feita a seguinte pergunta: "Você acha importante possuir um controle de gastos e receitas?”. As respostas estão na Figura 4.

Figura 4. Importância de possuir o controle de gastos e receitas.

\section{Importância de Possuir Controle de Gastos e Receitas}

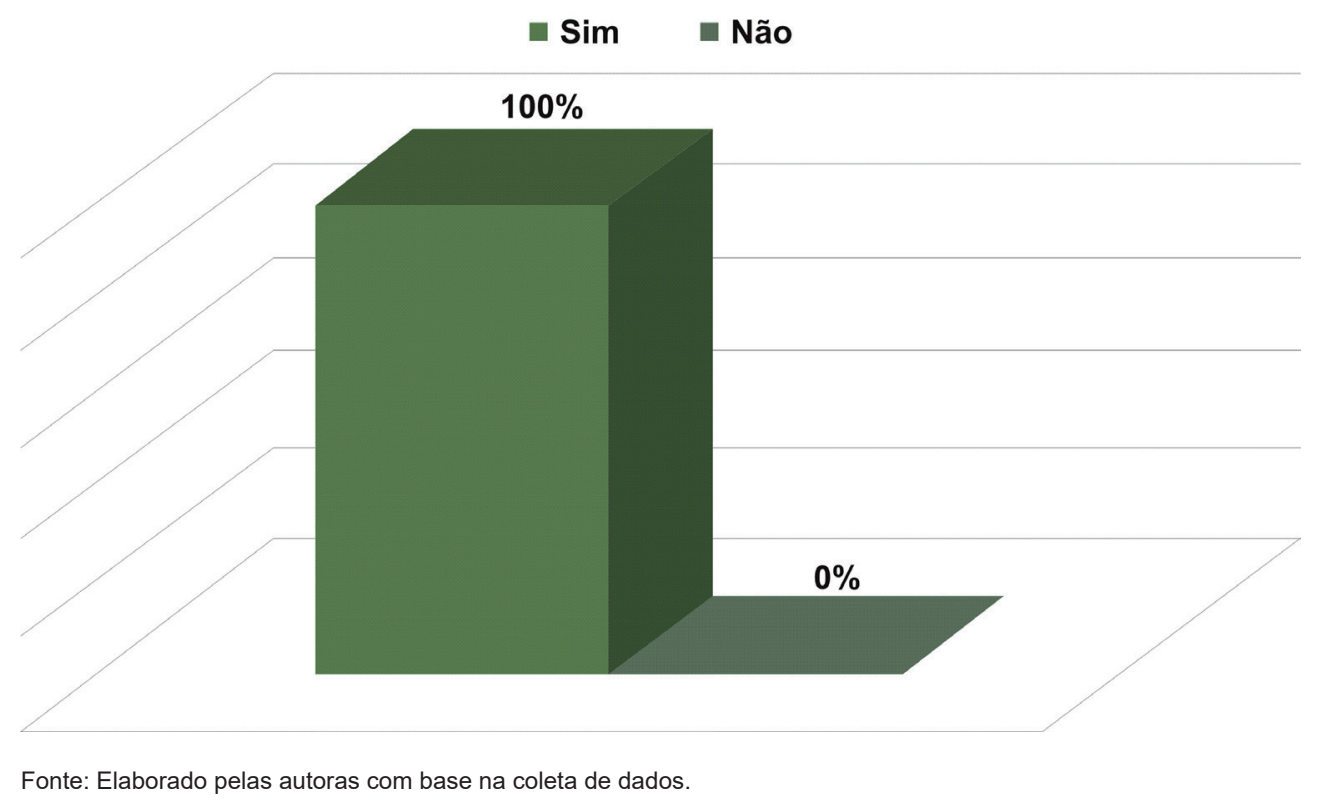

A Figura 4 demonstra que todos os entrevistados concordaram que é importante possuir um controle de gastos e receitas dos produtos ofertados na feira. Tal opinião resulta em consenso entre os integrantes da amostra, ao reconhecerem a importância de se ter um acompanhamento sobre seu próprio negócio. Alguns motivos foram mencionados sobre essa importância, como, por exemplo: conhecer quanto foi investido na atividade e qual o retorno sobre esse valor; saber se está valendo a pena manter a atividade no volume que está sendo praticada.

Esse questionamento objetivou trazer uma reflexão aos que responderam o questionário, sobre a importância da utilização desses controles contábeis para a gestão do seu pequeno negócio. Mesmo que a conscientização dessa importância seja observada na totalidade das respostas, conforme a Figura 4, a valorização da contabilidade não tem sido colocada em prática por alguns participantes da Agroufam, atores desta pesquisa.

\section{Considerações Finais}

A pesquisa retratou o cenário encontrado na $55^{\mathrm{a}}$ edição da Agroufam, a respeito das práticas contábeis de parcela dos participantes dessa edição que se disponibilizou a responder aos questionários. Foi possível verificar a presença de alguns controles contábeis por meio de anotações, em cadernos, dos agricultores e artesões entrevistados. Dentre esses controles foi observado que alguns se preocupam em registrar suas vendas; outros, os seus custos de produção. Todavia, percebeu-se que, mesmo que a totalidade dos entrevistados julgue importante manter os controles 
contábeis do seu negócio, nem todos o fazem. Assim sendo, esta pesquisa alcançou os seus objetivos, esclarecendo a questão do uso de controle contábil na feira Agroufam por parte de alguns dos seus participantes.

Para futuras pesquisas, sugere-se a aplicação dos mesmos questionamentos a uma parcela maior ou até mesmo à totalidade de agricultores e artesões em outra edição da feira Agroufam, podendo também expandir-se para outras feiras, levando em consideração a importância de explicar e mostrar aos participantes das feiras os benefícios da contabilidade, a fim de melhorar os conhecimentos dos seus negócios, estudando a possibilidade de controle dos custos, e consequentemente, dos preços de vendas final para a população consumidora das feiras de Manaus.

\section{Referências}

CREPALDI, S. A.; CREPALDI, G. S. Contabilidade de custos. 6. ed. São Paulo: Atlas, 2018.

FACHIN, O. Fundamentos da metodologia: noções básicas em pesquisa científica. 5. ed. São Paulo: Saraiva, 2006.

FERREIRA, R. J. Contabilidade de custos: teoria e questões comentadas conforme a lei das S/A e pronunciamentos do CPC. 10. ed. Rio de Janeiro: Ferreira, 2016.

FRAXE, T. de J. P.; CASTRO, A. P. de; SANTIAGO, J. L. Agroecologia em sociedades amazônicas. Manaus: Editora \& Gráfica Moderna, 2015.

IUDÍCIBUS, S. de. Contabilidade gerencial. 6. ed. São Paulo: Atlas, 1998.

JIAMBALVO, J. Contabilidade gerencial. 3. ed. Rio de Janeiro: LTC, 2009.

MARION, J. C.; RIBEIRO, O. M. Introdução à contabilidade gerencial. São Paulo: Saraiva, 2011.

PADOVEZE, C. L. Contabilidade gerencial. 3. ed. São Paulo: Atlas, 2000.

RIBEIRO, O. M. Contabilidade de custos. 5. ed. São Paulo: Saraiva, 2018.

UNIVERSIDADE FEDERAL DO AMAZONAS. Núcleo de Socioeconomia - NUSEC. Fortalecimento da organização social e identificação de mercados potenciais, visando sustentabilidade econômica em comunidades rurais do Amazonas. Relatório Técnico Parcial. Manaus, 2015. 190 p.

VANDERBECK, E. J.; FAGY, C. F. Contabilidade de custos. 11. ed. São Paulo: Cengage Learning, 2001. 
